\title{
バナッハ空間における条件付最適制御問題
}

一内点法による考察—

\author{
小 林 幹 夫・大 島 康次郎 \\ 東京大学生産技術研究所 東京都港区六本木 7-22-1 \\ (昭和 46 年 8 月 12 日 受付)
}

\section{Constrained Optimal Control Problems in Banach Spaces}

\section{— Approach by Means of Interior Penalty Method-}

\author{
Mikio Kobayashi and Yasujiro Oshima \\ (Institute of Industrial Science, University of Tokyo, Minato-ku, Tokyo) \\ (Received August 12, 1971)
}

\begin{abstract}
A necessary and sufficient condition for an optimal solution of the constrained optimal control problem in Banach space has been derived by means of an exterior penalty by the authors.

The purpose of this paper is to derive the similar condition by means of an interior penalty method.

It is shown that a series of the approximate solutions converges to the optimal one weakly and a series of the values of the cost functional generated from those approximate solutions converges to the optimal value. Using those results, the necessary and sufficient condition is derived by considering the minimization problem of a new functional.

In the main problem considered here, the control and state variables are defined in $L^{p}(1<p \leq \infty)$ or Euclidean space. The constraints are described by equalities and inequalities, where the equality constraints are defined in $L^{p}$ or Euclidean space and the inequality constraints are defined in $L^{\infty}$ or Euclidean space.
\end{abstract}

\section{1. 緒 \\ $\overline{\overline{⿳ 亠 二 口}}$}

バナッハ空間に括ける条件付最適制御問題を外点法 により考察し，最適解が満たすべき必要十分条件を導 出することはすでになされている1). 外点法と内点法 は互いに独立した対称的な手法であるので, 内点法に よっても上述のものと類似した条件が導出されるであ ろうといらことは直観的に想像できることである.

本研究は, この観点に立ち, 内点法によりバナッハ 空間に扣ける条件付最適制御問題の最適解が満たすべ き必要十分条件を導出することを目的としている.な 括，本稿では必要十分条件が得られるという1つの可 能性を実際に示すことと内点法特有の性質を考慮しつ つ，できるだけ広範囲の問題に対してそのような条件 を導出することに重点をおいている. 後者のことがら
は特に重要であると考えられるので, これに関して簡 単な説明をして物こう。

内点法に和いて導入される重久関数の不連続性扣よ び得られる近似解の性質，すなわち，不等式拘束条件 を満足しているという性質は外点法に牤いてはみられ ないものである．前者の性質は一般に種々の問題の解 析に困難性をもたらす原因となる，後者のそれは，近 似解法としては最も重要な利点とな⿰ているが，必要 十分条件を導出するといらことに関しては先の性質之 同様にある種の困難性をもたらすものである.したが って, 内点法の場合は諸問題の解析上なんらかの制限 をうけることになるであろう。

ここで考察される主問題においては，制御変数括よ び状態変数は $L^{p}$ あるいはユークリッド空間で定義さ れる. 拘束条件は等式抽よび不等式で与えられ，等式 
拘束条件は $L^{p}$ あるいはユークリッド空間, 不等式拘 束条件は $L^{\infty}$ あるいはユークリッド空間で定義される。

本稿の前半は, 近似解脑よび評価関数の近似值の収 束性が考察される. 後半は, 前半で得られた結果を用 いて必要十分条件が導出される.

得られた結果は，連続時間系あるいは離散時間系に 和ける状態变数あるいは制御变数制限付最適制御問題 に適用することができる。

\section{2. 最適制御問題と解の存在性}

ある集合 $D$ の上で定義される実数値関数の集合とあ るノルムによって構成されるバナッ八空間を $B_{i}(D)$ とする. 本稿では, 特に必要がない限り $B_{i}(D)$ を単 に $B_{\imath}$ と表わす. 制御变数招よび状態変数をそれぞれ $u$ 抢よび $z$ で表わし， $u \in B_{1}$ 㧊よび $z \in B_{2}$ とする. 写像,

$$
z=z(u) ; B_{1} \rightarrow B_{2}
$$

は連続であるものとする，評価関数は，

$$
f(z, u), f \in R^{1}
$$

で与兄られる. ここで, $R^{i}$ は $i$ 次元ユークリッド空

間を表わす，不等式扔よび等式拘束条件は，

$g(z, u) \leqq 0, h(z, u)=0, \quad g \in B_{3}, h \in B_{4}$

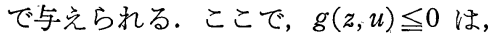

$$
\text { ess } \sup _{D} g_{i}(z, u) \leqq 0, \quad i=1,2, \cdots, m_{3}
$$

を意味する. 本稿では簡単のため, 写像 $\phi(z, u)$ を $\phi(u)$ あるいは $\phi$ と同一視する.

最適制御問題はつぎのよらになる.

【問題 1】（2）式で与兄られる拘束条件を満足し， (1)式で与兄られる $f(z, u)$ を最小にする $u_{0} \in B_{1}$ を 求めよ.

本稿では，前提条件となる事項を $A()$ で表わす。

A $1 f(u)$ 抢よび $g(u)$ は $u$ 亿関して連続であ り，凸である. $h(u)$ は $u$ に関して連続であり, 定数 項を除いて $u$ に関して線形である。

A 2 到 は回帰的である.

A $3 \quad U \equiv\left\{u \mid g(u) \leqq 0, h(u)=0, u \in B_{1}\right\} \neq \phi$

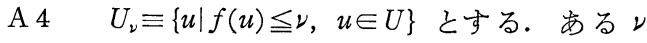
に対して $U_{\nu} \neq \phi$ であり， $U_{\nu}$ は有界である.

【補題 1】条件 $\mathrm{A} 1 \sim \mathrm{A} 4$ のもとで問題 1 の解が 存在する(1),2).

\section{3. 補助問題の記述}

この章では，近似解を得るために問題 1 亿対する補 助的な問題を設定し，それに関する若干の性質につい ての考察をする.

はん関数,

$$
I(u, n)=f(u)+s_{n} L(u)+r_{n} M(u)
$$

を導入する．ここで，

$$
\begin{aligned}
& L(u)=\sum_{i=1}^{m_{3}}\left\langle 1 / g_{i}(u),-1\right\rangle, \\
& M(u)=\|h(u)\|^{d}, \quad 1<d<\infty
\end{aligned}
$$

である.〈・〉は $B_{i}$ 飞物ける内積を表わし，\|・\|は

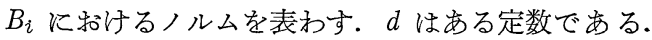
さらに,

$$
\left.\begin{array}{lll}
s_{n}>s_{n+1}>\cdots \cdots \cdots, & s_{n} \rightarrow 0 & (n \rightarrow \infty) \\
0<r_{n}<r_{n+1}<\cdots, & r_{n} \rightarrow \infty & (n \rightarrow \infty)
\end{array}\right\}
$$

である、つぎの定義をして报く。

$$
\begin{aligned}
& V_{\varepsilon_{m}} \equiv\left\{u \mid g(u) \leqq-\varepsilon_{m}, \quad u \in B_{1}\right\} \\
& V \equiv\left\{u \mid g(u) \leqq 0, \quad u \in B_{1}\right\} \\
& V_{0} \equiv\left\{u \mid g(u)<0, \quad u \in B_{1}\right\}
\end{aligned}
$$

ここで, $g(u) \leqq-\varepsilon_{m}$ は $g_{i}(u) \leqq-\varepsilon_{m}\left(i=1,2, \cdots, m_{3}\right)$ を意味し， $\varepsilon_{m}>\varepsilon_{m+1}>\cdots, \varepsilon_{m} \rightarrow 0(m \rightarrow \infty)$ である.

近似解を得るための問題はつぎのようになる。

【問題 2】固定された $\varepsilon_{m}$ に対して $I(u, n)$ を最 小にする $u_{n}\left(\varepsilon_{m}\right) \in V_{\varepsilon_{m}}$ を求めよ.

A $5 \quad V_{n, \nu} \equiv\left\{u \mid f(u)+r_{n} M(u) \leqq \nu, u \in V\right\} \quad$ とす る，各々の $n$ 物よびレに対して $V_{n, \nu}$ は有界である.

A $6 \quad U_{\varepsilon_{m}} \equiv\left\{u \mid g(u) \leqq-\varepsilon_{m}, h(u)=0, u \in B_{1}\right\}$ と する.このとき，適当な $\varepsilon_{m}$ 亿対して $U_{\varepsilon_{m}} \neq \phi$ である。

【補題 2】 条件 $A 1$ A 5 のもとでつぎのことが らが成立する1)。

（a） $V$ の上ではん関数 $I_{1}(u, n) \equiv f(u)+r_{n} M(u)$ の最小值が存在する.

（b） $V$ 上での $I_{1}(u, n)$ 最小点を $u_{n}{ }^{1}$ とすると，

$$
\lim _{n \rightarrow \infty} I_{1}\left(u_{n}{ }^{1}, n\right)=\lim _{n \rightarrow \infty} f\left(u_{n}{ }^{1}\right)=f\left(u_{0}\right)
$$

である。

【補題 3】条件 $\mathrm{A} 1 \sim \mathrm{A} 6$ のもとで問題の解が存 在する3).

問題 2 飞扮いては, $I(u, n)$ の最小化を $V\left(\varepsilon_{m}=0\right)$ の上でなく， $V_{\varepsilon_{m}}$ の上で行な拉うとしているわけであ るが,これは $V$ の上では $I(u, n)$ が不連続となり解の 存在性を保証することが困難であるということと， あ

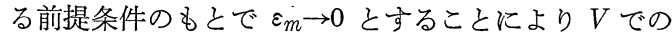
解が存在する場合の考察を簡明にしようとするためで ある。

補題 3 がい兄てかつ近似解怙よび評価関数の近似值 がそれぞれ最適なものに収束（強または弱）すること がいえれば，近似解法としてはいち扣う満足できるが， それだけでは最適解に対する必要十分条件を導出する ための具体的手段とはならない，これを行ならために は，まず取扱われる問題をさらに限定し， $I(u, n)$ の 最小値が $V$ 上で澾せられかつその最小点が $V_{0}$ に属 
することを必要とする。

つぎに述べるような前提条件を導入して抗こう。

A 7 ある関数列 $\left\{u_{l}\right\} \subset V$ に対して,

$$
\lim _{l \rightarrow \infty}\left[\operatorname{ess} \inf _{D}-g_{i}\left(n_{l}\right)\right]=0
$$

が成立しているならば，このときつね忹，

$$
\lim _{l \rightarrow \infty}\left\langle 1 / g_{i}\left(u_{l}\right),-1\right\rangle=+\infty
$$

となる。

【定理 1】条件 $\mathrm{A} 1$ ～A 7 が満足されているなら ば, $V$ での $I(u, n)$ の最小值が存在し, その最小点 は $V_{0}$ の要素である.

【証明】ある固定された $n$ に詨して, $I\left[u_{n}\left(\varepsilon_{m}\right), n\right] \geqq I\left[u_{n}\left(\varepsilon_{m+1}\right), n\right]>f\left(u_{0}\right)$

が成立する. $\left\{I\left[u_{n}\left(\varepsilon_{m}\right), n\right]\right\}$ は有界な 単調非増大列 であるから，ある值 $I(n)$ に収束する．任意の正の $\varepsilon$ が与兄られたとき， $M$ を十分大きくとれば $m>M$ な るすべての $m$ に対して,

$$
I\left[u_{n}\left(\varepsilon_{m}\right), n\right]<I(n)+\varepsilon
$$

が成立する. いっぽら, 補題 2 和よび条件 A 7 から, 任意の $N>\varepsilon$ が与えられたとき，十分大きな $M_{1}$ を 選べば $m>M_{1}$ なるすべての $m$ に対して，

$$
\begin{gathered}
s_{n} L(\bar{u})>N+I(n)-I_{1}\left(u_{n}{ }^{1}, n\right), \\
\forall \bar{u} \in\left\{V-V_{\varepsilon_{m}}\right\}
\end{gathered}
$$

を成立させることができる。ここで，

$$
\left\{V-V_{\varepsilon_{m}}\right\} \equiv\left\{v \mid v \cap V_{\varepsilon_{m}}=\phi, v \in V\right\}
$$

である.さらに，

$$
\begin{aligned}
I(\bar{u}, n) & =I_{1}(\bar{u}, n)+s_{n} L(\bar{u}) \\
& >I_{1}\left(u_{n}{ }^{1}, n\right)+N+I(n)-I_{1}\left(u_{n}{ }^{1}, n\right) \\
& =N+I(n)
\end{aligned}
$$

が成立する。（6)和よび(8)式から，

$$
I\left[u_{n}{ }^{1}\left(\varepsilon_{m}\right), n\right]<I(n)+\varepsilon<I(n)+N<I(\bar{u}, n)
$$

が得られる. したがって, なり得ない.けっきょく, $V$ での $I(u, n)$ の最小值 が存在する. その最小点を $u_{n}$ とすると,

$$
u_{n} \in V_{\varepsilon_{m}} \subset V_{0}
$$

である.

【補題 4】条件 $\mathrm{A} 1$ ～A 7 のもとでつぎのことが らが成立する。

( a) $\lim _{n \rightarrow \infty} f\left(u_{n}\right)=f\left(u_{0}\right)$

（b） $\left\{u_{n}\right\}$ の任意の部分列はある $u_{0}$ に弱収束す る部分列を含む.

\section{【証明】}

（a） $\left\{U_{\varepsilon_{m}}\right\}$ ，は $U$ で稠密であるから，任意の正の $\varepsilon$ が与兄られたとさ，ある整数 $N$ および $M$ が存在し て $n>N$ なるすべての $n$ と $m>M$ なるすべての $m$ に対して,

$$
\begin{aligned}
& s_{n} L(\bar{u})+r_{n} M(\bar{u})<\varepsilon / 2, \\
& f(\bar{u})<f\left(u_{0}\right)+\varepsilon / 2
\end{aligned}
$$

を満足する $\bar{u} \in U_{\varepsilon_{m}}$ が存在する. $U_{\varepsilon_{m}} \subseteq V_{\varepsilon_{m}}$ だから，

$$
I\left(u_{n}, n\right) \leqq I(\bar{u}, n)<f\left(u_{0}\right)+\varepsilon
$$

が成立する. いっぽう， $u_{n}$ は $V$ ので $I(u, n)$ の 最小点になっているから，

$$
I_{1}\left(u_{n}{ }^{1}, n\right) \leqq I_{1}\left(u_{n}, n\right)<I\left(u_{n}, n\right)
$$

が得られる.（9），(10）和よび補題 2 の（b) から, $n>N$ なるすべての $n$ に対して，

$$
f\left(u_{0}\right)-\varepsilon<I_{1}\left(u_{n}{ }^{1}, n\right)<I\left(u_{n}, n\right)<f\left(u_{0}\right)+\varepsilon
$$

となる。すなわち，

$$
\begin{aligned}
& \lim _{n \rightarrow \infty} f\left(u_{n}\right)=f\left(u_{0}\right), \\
& \lim _{n \rightarrow \infty} s_{n} L\left(u_{n}\right)=\lim _{n \rightarrow \infty} r_{n} M\left(u_{n}\right)=0
\end{aligned}
$$

が得られる。

(b), $\bar{V}_{n, \nu} \equiv\{u \mid I(u, n) \leqq \nu, u \in V\}$ とする. $\bar{V}_{n, \nu}$ の任意の要素 $u$ に対して,

$$
f(u)+r_{n} M(u)<f(u)+r_{n} M(u)+s_{n} L(u) \leqq \nu
$$

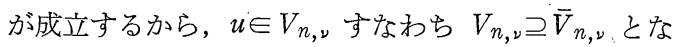
る. いっぽう, $V_{n+1, \nu}$ の任意の要素 $v$ に対して,

$$
f(v)+r_{n} M(v) \leqq f(v)+r_{n+1} M(v) \leqq \nu
$$

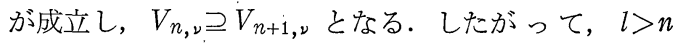
なるすべての $l$ に対して,

$$
\bar{V}_{l, \nu} \subseteq V_{n, \nu}
$$

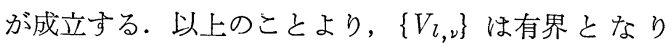
$\left\{u_{n}\right\}$ b有界となる.

$\left\{u_{n}\right\}$ の任意の弱収束部分列を $\left\{u_{m}\right\}$ とし，その弱 極限を $u^{*}$ とする. $u^{*} \in V$ であり，

$$
0=\lim _{m \rightarrow \infty} M\left(u_{m}\right) \geqq M\left(u^{*}\right) \geqq 0
$$

が成立するから，致は与えられた拘束条件 (2) を満 足する.したがって，

$$
f\left(u^{*}\right) \geqq f\left(u_{0}\right)
$$

となる. いっぽら，

$$
\begin{aligned}
f\left(u_{0}\right)=\lim _{m \rightarrow \infty} f\left(u_{n}\right) & =\underline{\lim f\left(u_{m}\right)} \\
& \geqq f\left(u^{*}\right)
\end{aligned}
$$

が成立するから，

$$
f\left(u^{*}\right)=f\left(u_{0}\right)
$$

となる. すなわら $u^{*}$ 、恼る最適解である。

\section{4. 必要十分条件の導出}

この章で扱う問題は $L^{p}$ あるいはユークリッド空間 で定義されるものに限定する. 3. までに得られた結 果を利用して $B_{1}$ のある要素が最適であるための必要 十分条件を導出する。

まず， $D$ および $B_{i}$ について具体的に説明する. $R^{n}$ に固定された座標を $n$ 次元べクトル $x$ で表わし, 
時刻を $t$ で表わす。 $D$ はつぎのように与えられる。

$$
D \equiv\left\{\begin{array}{l}
{[T, \Omega] \equiv[0, T] \times \Omega, \Omega \subseteq R^{n}} \\
\text { or } \\
R^{n} \quad
\end{array}\right.
$$

ここで, $[0, T]$ は時間区間を表わし，終端時刻 $T$ は 既知であるものとする． $\Omega$ 上で定義され，

$$
\left\{\Sigma \int_{\Omega}\left|y_{i}(x)\right|^{p} d x\right\}^{1 / p}<\infty, 1 \leqq p \leqq \infty
$$

を満足するすべての可測関数 $y=\left\{y_{1}, y_{2}, \cdots, y_{m}\right\}$ の 集合を $L^{p}(\Omega)$ とする。 $L^{p}(\Omega)$ そ抢けるノルムを(12) 式のはじめの不等式の左辺で定義し， $\|\cdot\| L^{p}(\Omega)$ とか き表わす．区間 $[0, T]$ で定義され，

$$
\left\{\int_{0}^{T}\|y(t)\|^{p} L^{p}(\Omega) d t\right\}^{1 / p}<\infty, y(t) \in L^{p}(\Omega)
$$

を満足するすべての可測関数の集合を $L^{p}(T, \Omega)$ で表 わす。 $L^{p}(T, \Omega)$ 飞特けるノルムを(13) 式のはじめの 不等式の左辺で定義し，\|・\|で表わす，以下に括いて は簡単のため $L^{p}(T, \Omega)$ と $L^{p}(D)$ を同一視 し, $R^{i}$ に和けるノルムは $L^{p}(D)$ の場合と同様に $\|\cdot\|$ で表

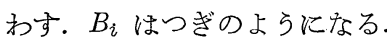

$$
\left.\begin{array}{l}
B_{1}=L^{a}(D), \quad 1<a<\infty ; \text { or } R^{m_{1}} \\
B_{2}=L^{b}(D), \quad 1<b \leqq \infty ; \text { or } R^{m_{2}} \\
B_{3}=L^{c}(D), \quad c=\infty ; \quad \text { or } R^{m_{3}} \\
B_{4}=L^{d}(D), \quad 1<d \leqq \infty ; \text { or } R^{m_{4}}
\end{array}\right\}
$$

以下に称いて， $B_{3}=L^{c}(D)$ あるいは $B_{4}=L^{d}(D)$ $(d=\infty)$ の場合は $D$ が有界であるるのとする，Dが 有界のときは，

$$
L^{\infty}(D) \subset L^{p}(D), 1 \leqq p<\infty
$$

となるので, $B_{4}=L^{d}(D) \quad(d=\infty)$ の場合は, 重み関 数を構成するさいは， $h(u)$ という写像をあらためて，

$$
h(u) ; L^{a}(D) \rightarrow L^{d^{\prime}}(D), \quad 1<d^{\prime}<\infty
$$

とみなすことにして， $L^{d^{\prime}}(D)$ での重み関数を用いる。 新しくはん関数,

$$
I\left(u, \lambda_{n}, \mu_{n}\right)=f(u)+\left\langle\lambda_{n}, g(u)\right\rangle+\left\langle\mu_{n}, h(u)\right\rangle
$$

を導入する.ここで，

$$
\begin{aligned}
\lambda_{n}= & s_{n}\left\{1 /\left[g_{1}\left(u_{n}\right)\right]^{2}, 1 /\left[g_{2}\left(u_{n}\right)\right]^{2}, \cdots, 1 /\left[g_{m_{3}}\left(u_{n}\right)\right]^{2}\right\}, \\
\mu_{n}= & r_{n} \cdot d\left\{\left|h_{1}\left(u_{n}\right)\right|^{d-1} \operatorname{sgn} h_{1}\left(u_{n}\right),\right. \\
& \left|h_{2}\left(u_{n}\right)\right|^{d-1} \operatorname{sgn} h_{2}\left(u_{n}\right), \cdots, \\
& \cdots,\left|h_{m_{4}}\left(u_{n}\right)\right|^{d-1} \operatorname{sgn} h_{m_{4}}(u \quad\},
\end{aligned}
$$$$
\operatorname{sgn} \alpha=\{1, \alpha>0 ; 0, \alpha=0 ;-1, \alpha<0\}
$$

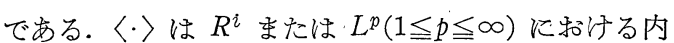
積を表わす. $\lambda_{n} \in L^{1}(D)$ または $\lambda_{n} \in R^{m_{3}}$ かつ $\lambda_{n}>0$ 拉よび $\mu_{n} \in B_{4}{ }^{*}$ であることは明らかである。ここで, $B_{i} *$ は $B_{i}$ の共役空間を表わす。

【補題 5】条件 $\mathrm{A} 1 \sim \mathrm{A} 7$ のもとで $I\left(u_{n}, \lambda_{n}, \mu_{n}\right)$ は $f\left(u_{0}\right)$ に収束する.

【証明】 $I\left(u_{n}, \lambda_{n}, \mu_{n}\right)=f\left(u_{n}\right)+\left\{-s_{n} L\left(u_{n}\right)+r_{n}\right.$. $\left.d M\left(u_{n}\right)\right\}$ である. 補題 4 の(a) の証明部分から,

$$
\lim _{n \rightarrow \infty} s_{n} L\left(u_{n}\right)=\lim _{n \rightarrow \infty} r_{n} M\left(u_{n}\right)=0
$$

である.このことと補題 4 の(a)から，

$$
\lim _{n \rightarrow \infty} I\left(u_{n}, \lambda_{n}, \mu_{n}\right)=\lim _{n \rightarrow \infty} f\left(u_{n}\right)=f\left(u_{0}\right)
$$

となる。

A $8 g(u)$ は $u$ 亿関してフレッシェ微分可能で ある.

【定理 2】条件 $\mathrm{A} 1$ 1 A 8 が満足されているなら ば, $u_{n}$ は $I\left(u, \lambda_{n}, \mu_{n}\right)$ の $B_{1}$ 上での最小点である.

【証明】 $u_{n}$ が $I\left(u, \lambda_{n}, \mu_{n}\right)$ を $B_{1}$ の上で最小に していないるのとして矛盾を導く. $u_{n}$ が $I\left(u, \lambda_{n}, \mu_{n}\right)$

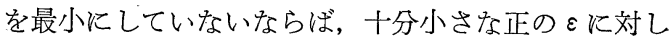
て,

$$
I\left(\bar{u}, \lambda_{n}, \mu_{n}\right)<I\left(u_{n}, \lambda_{n}, \mu_{n}\right)-\varepsilon
$$

を満足する $\bar{u} \in B_{1}$ が存在する.

$$
u_{\alpha}=\alpha \bar{u}+(1-\alpha) u_{n}, \quad 0<\alpha<1
$$

と物く. $u_{n} \in V_{0}$ であり, $B_{3}=L^{\infty}(D)$ または $B_{3}=R^{m_{3}}$ であるから， $\alpha$ を十分小さくとれば条件 A 1 から $u_{\alpha} \in V_{0}$ とすることができる. このような $u_{\alpha}$ に対し $\tau$,

$$
\begin{aligned}
I\left(u_{\alpha}, n\right)= & I\left(u_{n}, n\right)+I\left(u_{\alpha}, \lambda_{n}, \mu_{n}\right)-I\left(u_{n}, \lambda_{n}, \mu_{n}\right) \\
& +Q\left(u_{\alpha}\right)
\end{aligned}
$$

と表わすことができる、ここで，

$$
\begin{aligned}
& Q(\alpha)=s_{n} L\left(u_{\alpha}\right)-\left\langle\lambda_{n}, g\left(u_{\alpha}\right)\right\rangle-2 s_{n} L\left(u_{n}\right) \\
& \quad+r_{n} M\left(u_{\alpha}\right)-\left\langle\mu_{n}, h\left(u_{\alpha}\right)\right\rangle+r_{n}(c-1) M\left(u_{n}\right)
\end{aligned}
$$

である. (17)式の右辺の各項は点 $u_{n}$ においてフレッ シェ微分可能である. したがって，(17)式の右辺の第 1 行の $g_{i}$ を含えだ項を $q_{1 i}\left(u_{\alpha}\right)$ と拉くと,

$$
q_{1 i}\left(u_{\alpha}\right)=O(\alpha), \quad i=1,2, \cdots, m_{3}
$$

と特くことができる.ここで, $O(\alpha) / \alpha \rightarrow 0(\alpha \rightarrow 0)$ で ある.このことはつぎのようにして示される，条件 A 8 を使って，

$$
g_{i}\left(u_{\alpha}\right)=g_{i}\left(u_{n}\right)+\alpha \nabla g_{i}\left[u_{n} ; \vec{u}-u\right]+O(\alpha)
$$

とかき表わすことができる．ここで， $\nabla g_{i}\left[u_{n} ; \bar{u}-u\right]$

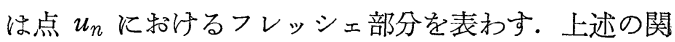
係式を用いて，

$$
\begin{aligned}
q_{1 i}\left(u_{\alpha}\right)= & s_{n}\left\{\left\langle 1 / g_{1}\left(u_{\alpha}\right),-1\right\rangle-\left\langle 1 / g_{i}{ }^{2}\left(u_{n}\right), g_{i}\left(u_{\alpha}\right)\right\rangle\right. \\
& \left.-2\left\langle 1 / g_{i}{ }^{2}\left(u_{n}\right),-1\right\rangle\right\} \\
= & s_{n} \cdot O(\alpha)
\end{aligned}
$$

が得られる。

(17)式の右辺の第 2 行についても同様のことがい光 るので, $h_{i}$ を含んだ項を $q_{2 i}\left(u_{\alpha}\right)$ と扰くと，

$$
q_{2 i}\left(u_{\alpha}\right)=O(\alpha), i=1,2, \cdots, m_{4}
$$

と抽くことができる. $m_{3}$ 拉よび $m_{4}$ は有限であるか ら, 


$$
Q\left(u_{\alpha}\right)=O(\alpha)
$$

と表わすことができる.したがって，(16)式は，

$$
\begin{aligned}
I\left(u_{\alpha}, n\right)= & I\left(u_{n}, n\right)+I\left(u_{\alpha}, \lambda_{n}, \mu_{n}\right)-I\left(u_{n}, \lambda_{n}, \mu_{n}\right) \\
& +O(\alpha)
\end{aligned}
$$

とかきな拈すことができる。

いっぽう, 条件 A 1 のもとで $I\left(u, \lambda_{n}, \mu_{n}\right)$ は $u$ に 関して凸であるから，

$$
I\left(u_{\alpha}, \lambda_{n}, \mu_{n}\right) \leqq \alpha I\left(\bar{u}, \lambda_{n}, \mu_{n}\right)+(1-\alpha) I\left(u_{n}, \lambda_{n}, \mu_{n}\right)
$$

が成立する（15)，(18)扔よび(19)式から，

$$
I\left(u_{\alpha}, n\right)<I\left(u_{n}, n\right)-\alpha \varepsilon+O(\alpha)
$$

となる、 $u_{\alpha} \in V_{0}$ であるから，この不等式は $u_{n}$ が $I\left(u_{n}, n\right)$ の $V$ での最小点であるといらことに矛盾す る. (証明終)

ここで, 定理 2 末でのことについてじゃっかんの説 明をして捄こう。

補題 3 までの考察だけでは必要十分条件は得られな いので，まず，定理 1 を導出せ妃ばならない。これを 行ならには条件 A 7 が必要となる. $g \in R^{m_{3}}$ の場合は 必然的に A 7 满足されることは明らかであろう. $g \in L^{\infty}(D)$ の場合は, 先の場合と異なり A 7 が常に 成立するということはない。したがって，具体的問題 を扱ら場合は，A７ が成立しているかどらか調べる必 要があるが，本稿ではこれに関する詳細な考察は割愛 する。

つぎに，定理 2 を導出する必要があるが，導出にさ いし，A7 の他に $g \in L^{\infty}(D)$ または $g \in R^{m_{3}}$ という ことが要求される。このことは特に重要なことである。 なぜならば，もし本質的に $g \in L^{p}(D)(1 \leqq p<\infty) な$ らば十分小さな正の $\alpha$ に対しても，一般に $u_{\alpha} \in V_{0}$ を 成立させることがでさないからである。

な特，定理が意味している大切なことは，的が単 に $V$ 上だげでなく $B_{1}$ 上での $I\left(u, \lambda_{n}, \mu_{n}\right)$ の最小点 になっているということである。内点法に拈いては， 近似解の属する領域は $V$ に限られているが，必要十 分条件を導出するにさいし，最終的にはこの拘束をと り除き， $B_{1}$ 上でのはん関数最小化問題に到達せねば ならない。

以上の議論からわかるように, 重み関数が $V$ 上で 不連続であるといらことと，最終的には最小化問題を $V$ 上でなく $B_{1}$ 上での問題に拡張しなけれればならない ということは，内点法にみられる特有の性質であり， この性質のため取扱われる問題の種類濑限が生ずる ことになる.

この章の残りの部分に扣いて，ぞのような前提条件 のもとで必要条件あるいは必要十分条件が導出される
か考察しよう。

以下に括いては，考察を容易にするために， $B_{3}$ 特 よび $B_{4}$ がニークリッド空間に限定された場合とそう でない場合に分けて議論する。

$3 \cdot 1$ 拘束条件が定義される空間をユークリッド空 間に限定した場合

この節では, $g \in \dot{R}^{m_{3}}$ およよび $h \in R^{m_{1}}$ の場合の問題 を扱う.この場合は $\left\{\lambda_{n} \vdots \mu_{n}\right\}$ の収束に関して弱位相 の導入は不要であり，かつ前提条件は単純なるのとな るので, 考察は比較的容易である. 他の場合の考察に さいしては，ここでの考察をできるだけ自然に拡張す るのがわかりやすいであろら。

A $9 . H \equiv\left\{h(u) \mid\|u\| \leqq \gamma, u \in B_{1}\right\}$ とする. ここで, $\gamma$ はある正の数である. $H$ は $R^{m_{4}}$ と淤ける原点を中 心とするある球を含む。

【定理 3】条件 $\mathrm{A} 1$ 1 A 8 のもとで,つぎのこと がらが成立する.

(a)， $\left\{\lambda_{n} \vdots \mu_{n}\right\}$ は有界である. $\left\{\lambda_{n} \vdots \mu_{n}\right\}$ の任意 の收束部分列を $\left\{\lambda_{m} \vdots \mu_{m}\right\}$ とし，その極限を $\left\{\lambda_{0} \vdots \mu_{0}\right\}$ とする.このとき $\lambda_{0} \geqq 0$ である.

(b) $I\left(u_{0}, \lambda_{0}, \mu_{0}\right) \leqq I\left(u, \lambda_{0}, \mu_{0}\right), \forall u \in B_{1}$; $\lambda_{0}, i \cdot g_{i}\left(u_{0}\right)=0$

条件 A 9 の 1 つの意味は, 原点 $h\left(u_{0}\right)$ の近傍は可 制御であるということである.

3.2 拘束条件が定義される空間をユークリッド空 間に限定しない場合

$g \in L^{\infty}(D)$ または $g \in R^{m_{3}}$ 打よび $h \in L^{d}(D)$ また は $h \in R^{m_{4}}$ の場合をまとめて考察する.

A $10 f(u)$ は $u$ 飞関してフレッシェ微分可能で ある. (A 10 終)

$f(u), f(u)$ 抢よび $h(u)$ の $u_{0}$ に掠けるフレッシ エ微分をとれぞれ $\varphi_{1}(u), \varphi_{2}(u)$ および $\varphi_{3}(u)$ とする。 ここで， $\varphi_{1}$ は $B_{1}$ から $R^{1}$ への， $\varphi_{2}$ は $B_{1}$ から $B_{3}$ への, $\varphi_{3}$ は $B_{1}$ から $B_{4}$ への有界線形作用素であり, フレッシェ導関数である.

\section{A 11}

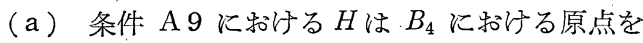
中心とするある球に括いて稠密な集合を含む.

(b) $w(u) \equiv\left\{\varphi_{2}(u) \vdots \varphi_{3}(u)\right\}$

$$
W \equiv\left\{w(u) \mid\|u\| \leqq \gamma^{\prime}, u \in B_{1}\right\}
$$

とする. ここで， $\gamma^{\prime}$ はある正の数である.このとき， $W$ はある集合 $\Gamma^{\prime}$ 扔よび $\Gamma^{\prime \prime}$ を含及， $\Gamma^{\prime}$ の1次結 合は， $B_{3}\left(D_{1}\right) \times B_{4}\left(D_{1}\right)$ でいたる所稠密であり， $\Gamma^{\prime \prime}$ のそれは $B_{4}\left(D_{2}\right)$ でいたる所稠密である.ここで， $D_{1} \cup D_{2}=D$ かつ $D_{1} \cap D_{2}=\phi$ である.さらに， $G \equiv\left\{g \mid g \leqq 0, \quad g \in B_{3}(D)\right\}$ 
としたとき， $D_{2}$ 上のほとんどいたる所で $g\left(u_{0}\right)$ は $G$ の内点である.

【定理 4】条件 $\mathrm{A} 1 \sim \mathrm{A} 8, \mathrm{~A} 10 \sim \mathrm{A} 11$ のもとで, つぎのことがらが成立する。

(a) $\left\{\lambda_{n} \vdots \mu_{n}\right\}$ 法弱收束する. その弱極限を $\left\{\lambda_{0} \vdots \mu_{0}\right\}$ とする. このとさ $\lambda_{0} \geqq 0$ である.

(b) $I\left(u_{0}, \lambda_{0}, \mu_{0}\right) \leqq I\left(u, \lambda_{0}, \mu_{0}\right), \quad \forall u \in B_{1}$; $\lambda_{0, i} \cdot g_{i}\left(u_{0}\right)=0$

条件 A 11 の (a)の 1 つの意味は, $B_{4}$ の原点 $h\left(u_{0}\right)$ の近傍は隼可制御であるといらことである. 一般に, 関数空間の制御問題では, 完全可制御であるといら条 件を課すことは適当でない場合が多いと考えられる。 このこととともに学的意味を失わないといら意味か らも目標点の近傍が準可制御であるといら条件を課す ことは，いち抢う，妥当なことであると考光られる。

【定理 5】定理 3 または定理 4 が成立しているも のとする.このとき，ある $u_{0} \in B_{1}$ が最適であるため の必要十分条件は，任意の $u \in B_{1}, \lambda \in B_{3}{ }^{*}, \lambda \geqq 0$, $\mu \in B_{4}{ }^{*}$ に対してある $\lambda_{0} \in B_{3}{ }^{*}, \lambda_{0} \geqq 0, \mu_{0} \in B_{4}{ }^{*}$ が存 在して,

$$
I\left(u_{0}, \lambda, \mu\right) \leqq I\left(u_{0}, \lambda_{0}, \mu_{0}\right) \leqq I\left(u, \lambda_{0}, \mu_{0}\right)
$$

が成立することである，ここで， $g \in L^{\infty}(D)$ の場合は $B_{3}{ }^{*} \equiv L^{1}(D)$ とする． $B_{4}$ についても同様である.

定理 3〜 5 の証明は文献 1）の場合とほぼ同様とな るので省略する。

\section{5. 結}

\section{言}

バナッ八空間に括ける不等式和よび等式拘束条件付 最適制御問題が内点法により考察された. 定理 1 亿抏 いては, $V$ 上でのはん関数 $I(u, n)$ の最小值が存在 乙その最小点は $V_{0}$ の要素となっていることが示され た．この定理を導出するさいに， $L(u)$ の不連続性が 問題となり, 外点法に扣いては不必要な条件 A6 が
必要となっている，この条件が成立しているような問 題を具体的にとり上げて詳細な考察をすることは重要 なことがあるが，本稿は関数空間に扔いて定性的な議 論をすることに重点を拗いているので, このことは省 略した.

定理 2 では, $I(u, n)$ の $V$ 上での最小点が $I\left(u, \lambda_{n}\right.$, $\left.\mu_{n}\right)$ の $B_{1}$ 上での最小点になっていることが示された. 内点法では $V$ から $B_{1}$ 上への拡張が不可欠のことで あり，このことを実現するために，現在のところ $g(z, u)$ の属する空間は本質的には $L^{\infty}$ またはユーク リッド空間泿定される。

定理 3 特よび定理 4 では $B_{1}$ のある要素が最適であ るための必要条件が導出され, 定理 5 では必要十分条 件が導出された。ここで大切なのは，近似解招よび $\left\{\lambda_{n}: \mu_{n}\right\}$ 飞関して強位相での収束性を必要とせず, 弱位相によるものだけで十分であるということである。 すなわち，弱位相の概念は; 評価関数の近似列の収束 を保証したり，㐌る関数列が強収束するための必要条 件を与えるということなどに有效に使われるばかりで なく，最適解が満たすべき必要十分条件を導出すると いうことに対しても有効に用いられるのである.

終わりに, 本研究に関して数学的な面で議論をして くださった, 東京大学物理工学科, 金子尚武助教授, 河原田秀夫講師拉よび東京大学生産技術研究所, 金子 幸臣助手に心から感謝する次第である。

\section{参 考 文 献}

1）小林・大島：バナッハ空間における条件付最適制御問 題 (計测自動制御学会論文集投稿中)

2) A.V.Balakrishnan, Optimal Control Problems in Banach Space, SIAMJ. Control, 3-1, 152/180

3）小林・大島：バナッハ空間に和ける条件付最適制御問 題の近似解法 (内点法に上る考察), 計測自動 制御学 会論文集， 8-5，584/590（1972）

4) N. Dunford and J. T. Schwartz, Linear Operators, Part I, Interscience (1958) 